\title{
Seroprevalence of lgG anti-Toxocara species antibodies in a population of patients with suspected allergy
}

This article was published in the following Dove Press journal:

International Journal of General Medicine

2I November 20II

Number of times this article has been viewed

\section{Rosanna Qualizza' \\ Cristoforo Incorvaia ${ }^{2}$ \\ Romualdo Grande ${ }^{3}$ \\ Eleni Makri \\ Luigi Allegra ${ }^{3}$}

'Allergy Service, ${ }^{2}$ Allergy/Pulmonary

Rehabilitation, Istituti Clinici di

Perfezionamento, ${ }^{3}$ IRCCS

Fondazione Cà Granda,

Milan, Italy
Correspondence: Rosanna Qualizza Istituti Clinici di Perfezionamento,

Via Farini, 9-20I58 Milan, Italy

Tel +3902 57994734

Fax +39025799 4749

Email rosanna.qualizza@icp.mi.it
Background: Toxocara canis is an intestinal nematode affecting dogs and cats, which causes human infection when embryonated eggs excreted in dog feces are ingested. Humans are paratenic hosts. Although the larvae do not develop into adult worms in the human body, they may migrate to various tissues and organs where they can survive for several years, giving rise to several clinical symptoms, which can present in allergy-like form.

Methods: Over 5 years, we examined 9985 patients referred for suspected allergies, based on symptoms such as dermatitis, urticaria, rhinitis, asthma, and conjunctivitis; 753 patients who had allergy tests negative or unrelated to clinical history were tested for seropositivity to T. canis by enzyme-linked immunosorbent assay (ELISA) or Western blotting (WB).

Results: In 240 patients (31.8\%), ELISA or WB or both tests were positive for T. canis immunoglobulin $\mathrm{G}(\mathrm{IgG})$ antibodies: in particular, 64 of them $(26.7 \%)$ were positive to ELISA, $110(45.8 \%)$ to $\mathrm{WB}$, and $66(27.5 \%)$ to both tests. Asthma was the most common clinical presentation. Two thirds of patients underwent subsequent anthelmintic therapy and showed a complete remission of symptoms and, in $43 \%$ of patients retested by ELISA and WB, became negative to Toxocara.

Conclusion: These findings strongly suggest that $T$. canis plays a significant role in inducing chronic symptoms presenting as suspected allergies.

Keywords: suspected allergy, Toxocara canis, enzyme-linked immunosorbent assay, Western blotting, anthelmintic therapy

\section{Introduction}

Allergic diseases in Western countries have steadily increased over the last 20 years, affecting the respiratory system, conjunctiva, and skin. ${ }^{1,2}$ Moreover, an emergent aspect is the association of gastrointestinal involvement with respiratory and/or cutaneous symptoms, arising from allergies and/or intolerance. Gastroenteric expressions of these diseases include acute symptoms (diarrhea or vomiting) and chronic symptoms (bloating, constipation which may alternate with diarrhea). Allergy tests, performed with commercial extracts or fresh foods, can be negative or slightly positive in most patients in both situations. ${ }^{3}$ Allergy tests may also be negative in respiratory and cutaneous allergy, and this enables a distinction between, eg, allergic and nonallergic asthma, allergic and nonallergic rhinitis, and allergic and nonallergic dermatitis. ${ }^{4}$

Different explanations for this increase in prevalence have been hypothesized, including genetic predisposition, 5,6 environmental factors, ${ }^{7,8}$ or the "hygiene hypothesis", 9 but none of these possibilities seems to be completely satisfactory. In this context, since the role of immunoglobulin E ( $\mathrm{IgE}$ ) antibodies is central to the development of 
allergies, factors related to the onset of symptoms must also include the possibility of helmintic infections, which induce high IgE levels. The IgE increase is proportional to both the severity of infection and invasion of parasites in the tissues, and is the sum of the total IgE level plus parasite-specific IgE release. ${ }^{10,11}$ The latter derives from helmintic production of factors that stimulate interleukin-4 production. ${ }^{12}$ In particular, one study found an increase in circulating IgE levels during parasitic infections caused by Ascarids, ${ }^{13}$ while other studies demonstrated a total IgE increase in parasitic diseases and their reduction after antiparasitic therapy, ${ }^{14}$ as well as high IgE levels in patients affected by visceral larva migrans with antibodies against Toxocara. ${ }^{15}$ The infestation caused by Toxocara canis appears to be very frequent in tropical countries, but also in some areas in Europe, especially among children in the first decade of life. ${ }^{16,17}$ The symptoms caused by Toxocara infection in the different target organs in the respiratory, cutaneous, and gastrointestinal systems are often similar to the symptoms of allergic diseases. The aim of the present study was to evaluate the prevalence of seropositivity to $T$. canis in a large population of patients referred for symptoms of suspected allergy.

\section{Methods and materials}

Between 2003 and 2008, we evaluated 9985 new patients presenting with symptoms suggesting an allergic disease. The clinical symptoms involved seasonal or persistent rhinoconjunctivitis, asthma, urticaria, angioedema, and dermatitis.

All patients underwent clinical examination, careful evaluation of symptoms, and allergy tests, including skin prick tests with inhaled or food allergen extracts and, in patients with dermatitis, patch tests with a standard panel of haptens (Merck, Milan, Italy). Skin prick tests were performed with the panel of allergen extracts from Stallergenes, Milan, Italy.

Routine and immunological blood tests and parasitological tests on feces were performed, as well as symptomatic therapy, environmental prophylaxis as preventive treatment, an exclusion diet when food allergy was suspected, and replacement of medication(s) when a drug allergy was suspected.

A subgroup comprising 753 patients was selected who suffered from chronic recurrent respiratory, eye, skin or gastrointestinal symptoms caused by nonallergic mechanisms, as assessed by results to allergy tests negative or unrelated to clinical history, and these patients underwent further hematochemical and immunological blood tests, ie, enzyme-linked immunosorbent assay (ELISA), measured in optical density (OD) with a range from 0.9 to 1.1 , and Western blotting (WB) tests for IgG antibodies to T. canis, using material from LTBio Diagnostics, Lyon, France. The results of WB were interpreted as shown in Figure 1. These patients mainly suffered from asthma, urticaria, dermatitis, and conjunctivitis; less frequently they suffered from gastroenteric symptoms, asthenia, headache, dizziness, or drug reactions. The prevalence of the different clinical presentations was compared using the Chi-squared test.

Anthelmintic therapy was prescribed for T. canis seropositive patients, using mebendazole (one $100 \mathrm{mg}$ tablet twice daily for 3 days, $5 \mathrm{~mL}$ syrup twice daily in children), repeated after 20 days up to three times in an effort to achieve significant symptomatic improvement. In the event of lack of improvement, albendazole (one $400 \mathrm{mg}$ tablet twice daily for 5 days in adults, $5 \mathrm{mg} / \mathrm{kg}$ divided in two half doses in children) was used, and repeated after two months. Drugs for symptomatic therapy were also prescribed. These were mainly antihistamines or topical steroids for rhinitis symptoms, inhaled beta-agonists and corticosteroids for asthma symptoms, antihistamines, and topical or systemic corticosteroids for skin symptoms, including

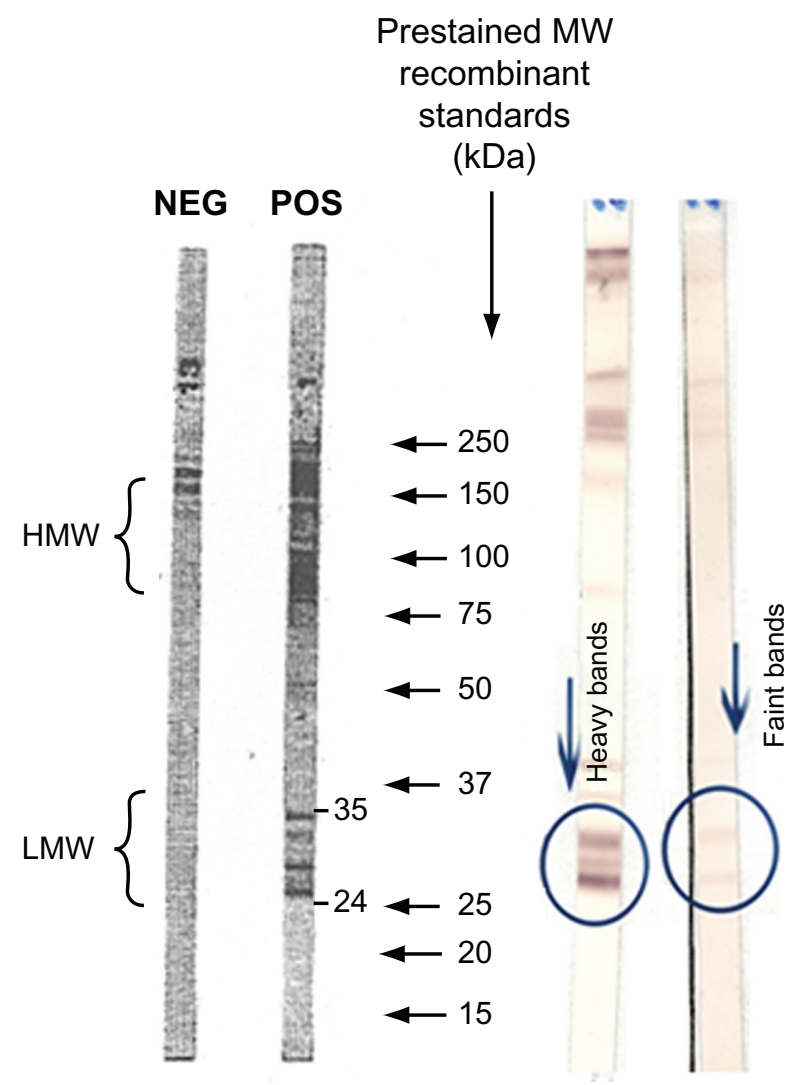

Figure I Western blot-specific IgG anti-Toxocara canis. Low molecular weight zone is Toxocara-specific. The presence on the strip of two or more low molecular weight bands in the range of $24-35 \mathrm{kDa}$ is indicative of the presence of specific antiToxocara lgG in the sample.

Abbreviations: kDa, kiloDalton; NEG, negative; POS, positive; HMW, high molecular weight; LMW, low molecular weight. 
urticaria/angioedema, dermatitis and itching, and probiotics (Lactobacillus reuteri) for intestinal symptoms. Regular control visits were scheduled, the first after 2 months and subsequently every 4 months. Patients who did not come back for the checkup visit were contacted by telephone about their symptoms. Clinical evaluations of symptoms and serological tests with the WB and ELISA for antibodies to T. canis were performed in patients who came to the visits. The study was registered (EudraCT number 2010-024221-20) and approved by local authorities. Informed consent was sought from all patients eligible for anthelmintic therapy.

\section{Results}

In the selected group of 753 patients suffering from chronic recurrent symptoms caused by nonallergic mechanisms, $240(31.8 \%)$ tested positive for T. canis by ELISA, WB, or both tests; 64 of them $(26.7 \%)$ were positive to ELISA, 110 (45.8\%) to $\mathrm{WB}$, and $66(27.5 \%)$ to both tests. These patients included 222 adults ( 150 females, 72 males, age range 18-72 years) and 18 children (seven females, 11 males, age range 2-17 years).

Sixty-two of the 753 patients $(25.8 \%)$ had animals at home (28 had a cat, 23 had a dog, and 11 had both animals). Fifty-two patients $(23.3 \%)$ were atopic, with positive results to skin prick testing that were unrelated to clinical symptoms; in these patients, the mean level of total $\operatorname{IgE}$ was $280 \mathrm{kU} / \mathrm{L}$. In the 188 nonatopic patients, the mean level of total $\operatorname{IgE}$ was $193 \mathrm{kU} / \mathrm{L}$.

The clinical presentations of the patients are reported in Table 1. Asthma was significantly more frequent compared with the other presentations $(P=0.029$ versus urticaria,

Table I Clinical presentation of patients positive to Toxocara canis

\begin{tabular}{lll}
\hline $\begin{array}{l}\text { Patients } \\
\text { n (\%) }\end{array}$ & $\begin{array}{l}\text { Clinical } \\
\text { presentation }\end{array}$ & $\begin{array}{l}\text { Prevalence in } \\
\text { selected population }\end{array}$ \\
\hline $59(24.6)$ & Asthma & $7.8 \%$ \\
$36(15)$ & Urticaria & $4.8 \%$ \\
$28(11.7)$ & Dermatitis & $3.7 \%$ \\
$19(7.9)$ & Conjunctivitis & $2.5 \%$ \\
$13(5.4)$ & Colitis & $1.7 \%$ \\
$12(5)$ & Headache & $1.6 \%$ \\
$12(5)$ & Asthenia & $1.6 \%$ \\
$11(4.6)$ & Cough & $1.5 \%$ \\
$10(4.2)$ & Dysphagia/angioedema & $1.3 \%$ \\
$8(3.3)$ & Itching & $1.10 \%$ \\
$7(2.9)$ & Rhinitis & $0.9 \%$ \\
$15(6.2)$ & Neurological symptoms & $1.9 \%$ \\
& (4 MS, 2 ataxia, I SLA, & \\
$10(4.2)$ & O ADHD, 5 epilepsy) & $1.3 \%$ \\
\hline
\end{tabular}

Abbreviations: MS, multiple sclerosis; SLA, systemic lupus erythematosus; ADHD, attention deficit hyperactivity syndrome.
$P=0.002$ versus dermatitis, $P<0.0001$ versus each other presentation). Among patients with asthma, five had level I, 30 had level II, 16 had level III, and eight patients had level IV disease according to the Global INitiative for Asthma (GINA) classification. Of the 240 T. canis seropositive patients, 162 (67.5\%) agreed to undergo anthelmintic therapy, which resulted in considerable improvement in symptoms. Eighty-eight patients did not come for the checkup visit, but they were contacted by phone and confirmed that they did not suffer from symptoms any longer and did not use any more symptomatic drugs. In 14 of the 74 patients who came back to the scheduled control visits, we observed both clinical and serological improvement in WB and ELISA tests. In six of these patients, a decrease in the size of bands using WB was found; in five patients, the size of bands using WB and the OD using ELISA decreased, and ELISA OD values decreased from $>1.1$ to negative values in the range of $0.9-1.0$ in three patients. There was a complete remission of symptoms with complete absence of antibodies to T. canis in 26 of the 74 patients. Table 2 shows the results of WB and ELISA.

\section{Discussion}

Because we have previously observed cases of $T$. canis infection that simulated allergic manifestations and were mistakenly considered allergies for a long time, ${ }^{18}$ we systematically tested allergic patients referred for suspected allergy (who had negative allergy tests or test results clearly unrelated to history) for seropositivity to T. canis. Of 753 patients with such characteristics, 240 (32\%) were positive using in vitro tests (ELISA or WB) for IgG antibodies to T. canis. The role of $T$. canis infection in sustaining the symptoms was further demonstrated by the efficacy of anthelmintic treatment, which was evident in more than two thirds of treated patients and was associated with negativization or a decrease in Toxocara IgG antibodies in $43 \%$ of patients who underwent repeat ELISA or WB.

Human toxocariasis is a zoonosis sustained by parasitic infestation with the nematode $T$. canis belonging to the order of Ascaris, which infects dogs, cats, and many other mammals. A human host is occasionally infected via accidental ingestion of embryonated eggs in dirt. This happens mainly among children when they ingest soil while playing or eating. In human hosts, the larvae do not develop into adults, but they can migrate to different organs and tissues and survive for long periods of time, varying from a few months to decades, depending on the host immune response. ${ }^{19}$

The real incidence/prevalence of this infestation in humans has not yet been assessed, because the disease induces 
Table 2 Changes in anti-Toxocara IgG antibodies as measured by ELISA and WB following anthelmintic treatment in clinically improved patients

\begin{tabular}{|c|c|c|}
\hline Patient & $\begin{array}{l}\text { Before treatment } \\
\text { ELISA WB }\end{array}$ & $\begin{array}{l}\text { After treatment } \\
\text { ELISA WB }\end{array}$ \\
\hline 1 & I.06 negative & $<0.9$ negative \\
\hline 2 & $>$ I.I negative & $<0.9$ negative \\
\hline 3 & $>$ I.I negative & $<0.9$ negative \\
\hline 4 & I.04 negative & $<0.9$ negative \\
\hline 5 & 0.92 negative & $<0.9$ negative \\
\hline 6 & $>$ I.I negative & $<0.9$ negative \\
\hline 7 & I.00 negative & $<0.9$ negative \\
\hline 8 & $>$ I.I negative & $<0.9$ negative \\
\hline 9 & $>$ I.I negative & $<0.9$ negative \\
\hline 10 & $<0.9$ faint bands & $<0.9$ negative \\
\hline 11 & $<0.9$ faint bands & $<0.9$ negative \\
\hline 12 & $<0.9$ faint bands & $<0.9$ negative \\
\hline 13 & $<0.9$ faint bands & $<0.9$ negative \\
\hline 14 & $<0.9$ faint bands & $<0.9$ negative \\
\hline 15 & $<0.9$ faint bands & $<0.9$ negative \\
\hline 16 & $<0.9$ faint bands & $<0.9$ negative \\
\hline 17 & $<0.9$ faint bands & $<0.9$ negative \\
\hline 18 & $<0.9$ faint bands & $<0.9$ negative \\
\hline 19 & $<0.9$ faint bands & $<0.9$ negative \\
\hline 20 & $<0.9$ faint bands & $<0.9$ negative \\
\hline 21 & $<0.9$ heavy bands & $<0.9$ negative \\
\hline 22 & $<0.9$ heavy bands & $<0.9$ negative \\
\hline 23 & I.00 faint bands & $<0.9$ negative \\
\hline 24 & $>$ I.I faint bands & $<0.9$ negative \\
\hline 25 & $>1 . I$ faint bands & $<0.9$ negative \\
\hline 26 & $>$ I.I negative & $<0.9$ negative \\
\hline 27 & $>1 . I$ heavy bands & $<0.9$ faint bands \\
\hline 28 & $>1 . I$ heavy bands & I.08 heavy bands \\
\hline 29 & $<0.9$ heavy bands & $<0.9$ faint bands \\
\hline 30 & 1.30 heavy bands & $<0.9$ faint bands \\
\hline 31 & $>I . I$ heavy bands & 0.99 heavy bands \\
\hline 32 & $>I . I$ heavy bands & $<0.9$ faint bands \\
\hline 33 & $>1 . I$ heavy bands & $>$ I.I faint bands \\
\hline 34 & $>1 . I$ faint bands & 0.99 negative \\
\hline 35 & $<0.9$ heavy bands & $<0.9$ faint bands \\
\hline 36 & 1.00 faint bands & $<0.9$ faint bands \\
\hline 37 & $<0.9$ heavy bands & $<0.9$ faint bands \\
\hline 38 & $>1 . I$ heavy bands & $>$ I.I faint bands \\
\hline 39 & $>1.1$ heavy bands & $<0.9$ faint bands \\
\hline 40 & $>1.1$ heavy bands & $>$ I.I negative \\
\hline
\end{tabular}

Abbreviations: ELISA, enzyme-linked immunosorbent assay; WB, Western blotting.

nonspecific symptoms. However, sometimes it mimics a viral infection, and in the mildest cases can be totally asymptomatic. Symptoms are classified based on three clinical outlines. The first one is called capsulated toxocariasis, which is characterized by very mild symptoms, with no clear clinical manifestations (for example, nonspecific illness with fever, recurrent hacking cough, insomnia, abdominal pain, headache, and behavioral disorders). The second one is called ocular larva migrans, limited to the eye, and may cause a reduction in sight, conjunctival hyperemia, recurrent conjunctivitis, and even granulomas, uveitis, and retinal detachment. The last one is visceral larva migrans, and its symptoms include fever, asthenia, behavioral depression (suggesting central nervous system involvement), skin afflictions like nodules, chronic hives, recurrent labial and eyelid angioedema and eczematous dermatitis, enteric symptoms such as meteorism and abdominal pain, respiratory symptoms such as dyspnea, persistent cough, recurrent asthmatic and bronchitic manifestations, pleuritis, and bronchopneumonia. ${ }^{17,19}$

Epidemiological studies conducted in Europe have shown variable prevalence of seropositivity for T. canis. In Spain, 14\% of both pediatric and adult patients were found to suffer from eosinophilia, and $6 \%$ of these patients showed eye disorders. ${ }^{20}$ In Sweden, the prevalence of seropositivity was about $7 \%$, indicating a relevant presence of subclinical toxocariasis. In this group, eosinophilia was recognized in $32 \%$ of the sample, and the most common clinical manifestation was eye problems (46\%) while neurological, respiratory and hepatic symptoms were described in $40 \%$ of these patients. $^{21}$

In an Italian study that included 2112 healthy adult subjects, the prevalence of $T$. canis antibody seropositivity was $3.9 \%$. The percentage increased in the control group of 471 nonhealthy subjects ( 257 affected by epilepsy, 142 by oligophrenia, 76 by Strongyloides stercoralis infestation), and was $4.35 \%$ in epilepsy patients, $9.2 \%$ in patients with strongyloidiasis, and $10.6 \%-14.5 \%$ in subjects with oligophrenia. ${ }^{22}$ Thirty-one of 100 Toxocara-positive pediatric patients suffered from asthma or bronchitis, while the percentage decreased to only $12 \%$ among Toxocara-seronegative patients in a study performed in The Netherlands. ${ }^{23}$

Toxocara infestation mainly occurs via accidental ingestion of soil, that is why the illness usually affects children, but adults can also be infected. As stated above, the larvae do not develop in the human host but only migrate to different organs and tissues, where they survive for a certain time period depending on the level of the host immune response. Clinical manifestations can be nonspecific and difficult to recognize. They may even cause symptoms similar to viral infections or allergy-like symptoms, ie, may present with the clinical expression of allergy.

Symptoms can be mild, including fever, recurrent hacking cough, dyspnea, recurrent bronchitis, pleuritis, bronchopneumonia, asthma, skin afflictions like nodules and chronic hives, recurrent labial and eyelid angioedema and eczematous dermatitis, enteric symptoms, or even symptoms limited to the eye causing conjunctiva hyperemia and 
recurrent conjunctivitis. ${ }^{18,19}$ Most of these symptoms were present in the population we studied, in particular asthma, which was significantly more frequent than any other clinical presentation in patients with positive in vitro tests for Toxocara. This reinforces the suggestion made by Cooper that $T$. canis is an important and neglected environmental risk factor for asthma. ${ }^{24}$ The role of T. canis infection may be assessed by the detection of specific IgG antibodies, it being known that the IgG4 subclass is predominantly involved in the response to parasitic infections. ${ }^{25}$

\section{Conclusion}

The findings from this study indicate that $T$. canis infection, as assessed by seropositivity of IgG antibodies by ELISA or WB, is not rare in patients presenting with symptoms of apparent allergy but with negative or inconclusive allergy tests. This suggests that serological tests should be performed to detect Toxocara-specific IgG antibodies in such patients and to assess the effect of anthelmintic treatment, in an effort to diagnose parasitic infection correctly in patients who are otherwise given a simple (but incorrect) diagnosis of nonallergic disease.

\section{Disclosure}

The authors report no conflicts of interest in this work.

\section{References}

1. The International Study of Asthma and Allergies in Childhood (ISAAC) Steering Committee. Worldwide variation in prevalence of symptoms of asthma, allergic rhinoconjunctivitis, and atopic eczema. Lancet. 1998; 351:1225-1232.

2. Asher MI, Montefort S, Bjorksten B, et al. ISAAC Phase Three Study Group. Worldwide time trends in the prevalence of symptoms of asthma, allergic rhinoconjunctivitis, and eczema in childhood: ISAAC Phases One and Three repeat multicountry cross-sectional surveys. Lancet. 2006; 368:733-743.

3. Sicherer SH, Sampson HA. Food allergy. J Allergy Clin Immunol. 2010; 125 Suppl 2:116-125.

4. Johansson SG, Bieber T, Dahl R, et al. Revised nomenclature for allergy for global use: report of the Nomenclature Review Committee of the World Allergy Organization. Oct 2003. J Allergy Clin Immunol. 2004;113:832-836.

5. Holgate ST. Genetic and environmental interaction in allergy and asthma. J Allergy Clin Immunol. 1999;104:1139-1146.
6. Cookson WO, Moffatt MF. Genetic of asthma and allergic disease Hum Mol Genet. 2000;9:2359-2364.

7. Von Mutius E, Martinez FD, Fritzsch C, Nicolai T, Roell G, Thiemann HH. Prevalence of asthma and atopy in two areas of West and East Germany. Am J Respir Crit Care Med. 1994;149:358-364.

8. Von Mutius E. The environmental predictors of allergic disease. J Allergy Clin Immunol. 2000;105:9-19.

9. Schaub B, Lauener M, von Mutius E. The many faces of the hygiene hypothesis. J Allergy Clin Immunol. 2006;117:969-977.

10. Rosenberg EB. Increasing circulating IgE in a new parasitic disease human intestinal capillariasis. $N$ Engl J Med. 1970;283:1148-1149.

11. Grove DI, Burston TO, Forbes IJ. Fall in IgE levels after treatment for hookworm. Clin Exp Immunol. 1974;18:565-569.

12. Yamaoka KA, Kolb JP, Miyasaka N, et al. Purified excretory-secretory component of filarial parasite enhances FceRII/CD23 expression on human splenic B and T cells and $\operatorname{IgE}$ synthesis while potentiating T-helper type 2-related cytokine generation from T cells. Immunology. 1994;81:507-512.

13. Lynch NR, Hagel I, Perez M, et al. Effect of anthelmintic treatment on the allergic reactivity of children in a tropical slum. J Allergy Clin Immunol. 1993;92:404-411.

14. Moqbel RM, Pritchard DI. Allergy and helminthic parasites: are atopics protected against infection? In: Kay AB, editor. Allergy and Allergic Diseases. Boston, MA: Blackwell Science; 1997.

15. Tullis DCH. Bronchial asthma associated with intestinal parasites. N Engl J Med. 1970;282:370-374.

16. Grove DI. What is the relationship between asthma and worms? Allergy. 1980;37:139-148.

17. Despommier D. Toxocariasis: clinical aspects, epidemiology, medical ecology, and molecular aspects. Clin Microbiol Rev. 2003;16: 365-372.

18. Qualizza R, Megali R, Incorvaia C. Toxocariasis resulting in seeming allergy. Iran J Allergy Clin Immunol. 2009;8:161-164.

19. Rubinsky-Elefant G, Hirata CE, Yamamoto JH, Ferreira MU. Human toxocariasis: diagnosis, worldwide seroprevalences and clinical symptoms of the systemic and ocular forms. Ann Trop Med Parasitol. 2010; 104:3-23.

20. Portùs M, Riera C, Prats G. A serological survey of toxocariasis in patients and healthy donors in Barcelona (Spain). Eur J Epidemiol. 1989;5:224-227.

21. Ljungstrom I, van Knapen F. An epidemiological and serological study of Toxocara infection in Sweden. Scand J Infect Dis. 1989;21:87-93.

22. Genchi C, Di Sacco B, Sangalli G, Scaglia M. Epidemiology of human toxocariasis in northern Italy. Parassitologia. 1990;32:313-319.

23. Overgaauw PA. Aspects of Toxocara epidemiology: human toxocariasis. Crit Rev Microbiol. 1997;23:215-231.

24. Cooper PJ. Toxocara canis infection: an important and neglected environmental risk factor for asthma? Clin Exp Allergy. 2008;38:551-553.

25. Bhattacharyya T, Santra A, Majumder DN, Chatterjee BP. Possible approach for serodiagnosis of ascaridiasis by evaluation of immunoglobulin G4 response using Ascaris lumbricoides somatic antigen. J Clin Microbiol. 2001;39:2991-2994.
International Journal of General Medicine

\section{Publish your work in this journal}

The International Journal of General Medicine is an international, peer-reviewed open-access journal that focuses on general and internal medicine, pathogenesis, epidemiology, diagnosis, monitoring and treatment protocols. The journal is characterized by the rapid reporting of reviews, original research and clinical studies across all disease areas.

\section{Dovepress}

A key focus is the elucidation of disease processes and management protocols resulting in improved outcomes for the patient.The manuscript management system is completely online and includes a very quick and fair peer-review system. Visit http://www.dovepress.com/ testimonials.php to read real quotes from published authors. 